\title{
BMJ Open Correlations of impulsivity and aggressive behaviours among adolescents in Shanghai, China using bioecological model: cross-sectional data from Global Early Adolescent Study
}

\author{
Chunyan Yu (D) , ${ }^{1}$ Jiashuai Zhang, ${ }^{2}$ Xiayun Zuo, ${ }^{1}$ Qiguo Lian (D , ${ }^{1}$ Xiaowen Tu, ${ }^{1}$ \\ Chaohua Lou'
}

To cite: Yu C, Zhang J,

Zuo X, et al. Correlations of impulsivity and aggressive behaviours among adolescents in Shanghai, China using bioecological model: crosssectional data from Global Early Adolescent Study. BMJ Open 2021;11:e043785. doi:10.1136/ bmjopen-2020-043785

- Prepublication history and additional supplemental material for this paper are available online. To view these files, please visit the journal online (http://dx.doi.org/10.1136/ bmjopen-2020-043785)

$\mathrm{CY}$ and JZ contributed equally.

Received 17 August 2020

Accepted 17 June 2021

Check for updates

(C) Author(s) (or their employer(s)) 2021. Re-use permitted under CC BY-NC. No commercial re-use. See rights and permissions. Published by BMJ.

For numbered affiliations see end of article.

Correspondence to

Dr Chaohua Lou;

louchaohua60@163.com

\section{ABSTRACT}

Objective To examine the correlations between impulsivity and aggressive behaviours among Chinese adolescents.

Design A school-based cross-sectional study.

Setting Three primary middle schools located in less developed communities of Shanghai.

Participants 1524 adolescents aged 11-16 years. Measures The impulsivity was measured by Barratt Impulsivity Scale, and the aggressive behaviours were determined by self-reports. Data were collected through computer-assisted self-interview using tablets. Multivariate Firth logistic regression model was conducted to examine correlations between total, attentional, motor, and non-planning impulsivity and aggressive behaviours, respectively.

Results Totally, $7.48 \%$ of participants reported aggressive behaviours toward others during the past 6 months. The proportion of aggressors among boys and girls was $10.60 \%$ and $4.18 \%$, respectively. Results of the multivariate regression suggested the risk of aggressive behaviours was significantly increased among those with the highest tertile of total impulsivity (adjusted $\mathrm{OR}(\mathrm{aOR})_{\text {boys }}=3.14,95 \% \mathrm{Cl}: 1.48$ to $6.65 ; \mathrm{aOR}_{\text {girls }}=3.74$, $95 \% \mathrm{Cl}: 1.10$ to 12.76$)$ and motor impulsivity $\left(\mathrm{aOR}_{\text {boys }}=2.91,95 \% \mathrm{Cl}: 1.46\right.$ to $5.82 ; \mathrm{aOR}_{\text {girls }}=3.57,95 \% \mathrm{Cl}$ : 1.25 to 10.20.), comparing with those with the lowest tertile, for boys and girls, respectively. Besides, younger age, lower social cohesion and being bullied within 6 months were associated with a higher risk of aggressive behaviours among girls. Less family caring and being bullied within 6 months were associated with the risk among boys.

Conclusions The present study indicates a positive association between impulsivity and aggressive behaviours, with a more salient correlation between motor impulsivity subtrait and aggressive behaviour among both boys and girls. Furthermore, adolescents' aggressive behaviours were affected by multiple factors from individuals, family, peers and community. Comprehensive intervention strategies such as controlling the aggressor's impulsivity, helping them better channel their anger, creating a better family, school and neighbourhood
Strengths and limitations of this study

- The study used a reliable and validated scale to access impulsivity among the participants.

- The findings warrant further exploration of the impulsiveness subscales to the understanding of aggressive behaviours critically.

- The simplified measurement of aggressive behaviour prevents the further distinction of impulsive aggressive behaviour from premeditated aggressive behaviour. Further studies are needed to explore how different facets of impulsivity play the role differently in these two forms.

environment, and providing support and services for victims of violence are needed.

\section{INTRODUCTION}

Aggression is a complex concept. It has traditionally been classified into two distinct subtypes, impulsive (also known as reactive or hostile) or premeditated (also known as proactive or instrumental). The former is characterised by uncontrolled and exaggerated responses to the stimuli, while the latter is defined as planned or conscious aggressive acts, not spontaneous or related to an agitated state. ${ }^{1}$ Though the division is not without meaningfulness to guide the prevention and intervention due to the potential harm it could cause, there were some criticisms of the dichotomous method of characterising aggressive behaviour as the distinction of the two is not that clear and it is the harm that should be concerned regardless the typology of the actions. ${ }^{2}$

Previous studies have indicated that aggressive behaviour was associated with a range of adverse outcomes in adolescence, such as the increased risk of depressive symptoms, 
delinquency, internet addiction and suicide attempts. ${ }^{3-6}$ In the school setting, aggressive behaviour was related to low academic performance scores and higher peer rejection. ${ }^{37}$ At the family level, significant relationships were observed between aggressive behaviour on the one hand and family conflict and low family cohesion on the other. ${ }^{3}$ More importantly, if aggressive behaviours become prevalent during this developmental stage, they can be escalated and persist. ${ }^{8}$ Evidence from longitudinal research has demonstrated that adolescents with higher aggression levels are at greater risk of criminal activity and violence, peer victimisation, rule-breaking behaviours, internalising symptoms, and narcissistic and borderline personality features in the future. ${ }^{9}{ }^{10}$ Furthermore, adolescents with higher aggressiveness tend to have difficulties in controlling waves of anger in adulthood and have consistently poorer outcomes across life success domains. ${ }^{11} 12$ Also, research has shown that high levels of aggression may result in high social costs because a range of services and resources are needed for delinquency, incarceration and unemployment. ${ }^{59}$

As a personality trait with a strong biological foundation, impulsivity was defined as a quick and unplanned response for internal or external stimuli regardless of the negative consequences for an individual or others. ${ }^{13}$ The definition of impulsivity does have overlaps with aggressiveness. It is also one of the main precursors of a set of antisocial behaviours and the basis for several pathological disorders such as attention-deficit/hyperactive disorder, borderline personality disorder and antisocial personality disorder. ${ }^{14-16}$ A great number of studies in western countries have demonstrated a positive association between impulsivity and aggression, ${ }^{71-19}$ both concurrently and longitudinally. However, such correlations were majorly explored among the forensic population or clinical sample, or taking the impulsivity as a whole (using the total impulsive score in the analysis)) instead of considering it as a multifacet construct.

Among adolescents, studies showed that impulsivity might not be a direct risk for aggression. Youth often cannot adequately manage their emotions when facing difficulties, leading them to behave in aggressive ways. ${ }^{20}$ Existing research also argues that behaviours resulting from motor impulsiveness are by nature unplanned or reactive. ${ }^{21}$ In contrast, behaviours resulting from attentional (cognitive) impulsiveness are more likely to be planned or proactive. The latter should be taken more attention and in consideration of targeted intervention or treatment. ${ }^{14}$ Other research showed that impulsivity was present in any type of aggressive act and did not distinguish between acts of premeditated or impulsive aggression. ${ }^{1622} 23$ Given the mixed results and their relevance to both healthy and harmful facets of the behaviours, the role of impulsivity still attracts a lot of attention. The question of whether a person is capable of modulating their cognition and behaviour to fit the demands of a given environment is imperative, ${ }^{14}$ which makes understanding the role of impulsiveness in the forming of aggression among healthy/ordinary population, especially among young adolescents who are at the critical developing stage urgent.

The present study is guided by Bronfenbrenner's bioecological model and Blum et al's conceptual framework for research targeting early adolescence, ${ }^{24}$ including family, school and neighborhood factors in the process of shaping youth's aggressive behaviour despite individual biological characteristics and personal traits. ${ }^{25}$ At the family level, family structure and parental connectedness would help buffer the anger. While in school, peer interactions exert significant influences on the conducting of aggressive behaviour. ${ }^{25}{ }^{26}$ Neighbourhood environment is another important but always neglected factor for shaping aggressive behaviour as it provides the scenario for multiple health risk behaviours. ${ }^{27}$ For adolescence, specifically, it is a critical period for curtailing aggressive behaviours as both impulsivity and sensation seeking (both relate to risk-taking behaviours) are at their peak during this developmental window according to the Dual System Model. ${ }^{21}$ The changes, stresses and disparities could arouse anger easily. ${ }^{8}$ According to Blum $e t a$ l s framework, ${ }^{24}$ adolescence is also a dynamic developmental period of learning and adaptation, which creates both vulnerabilities and unique opportunities for early intervention and prevention. Thus, the identification of risk factors is critical to the understanding of aggressive behaviours among adolescents.

There are also culturally bounded limits on acceptable levels of aggression or violent behaviours. Aggressive behaviours over the boundaries of acceptable levels are often considered harmful. ${ }^{28}$ Such cultural differences were noted by researchers both in the level of aggression and their correlations, reflected through the social environment and individual differences, including personality and cognition. ${ }^{23}$ In China, research on adolescents' impulsiveness was mainly focused on its impacts on internet addiction and self-injury or suicidal behaviour, ${ }^{29-31}$ while research on the association between impulsivity and aggressive behaviours was scant. We used the wave 2 cross-sectional data from the Global Early Adolescent Study (GEAS) in Shanghai to examine the correlations of impulsivity and aggressive behaviours with the consideration of covariates in the individual, family, school and neighbourhood level according to the bioecological model. GEAS is a multinational longitudinal study that focused on early adolescents in disadvantaged urban environments with a gender lens. For the present study, we hypothesised that (1) impulsivity would be positively correlated with young adolescents' aggressive behaviour, while the correlation would be strong among motor or non-planning impulsiveness and aggression; (2) ecological factors like family interactions, peer interactions and community environment would be influential in the forming of adolescents' aggressive behaviours. 


\section{METHODS}

\section{Study design and participants}

Data for this study were drawn from wave 2 of the GEAS investigation. A stratified cluster sampling procedure was adopted for the selection of participants in GEAS Shanghai site. Three primary public middle schools in two less developed subdistricts of the Jing'an district in Shanghai were selected, and the fieldwork was implemented with the coordination of key informants from the local teacher's organisation. All eligible students in grades 7-9 (the baseline investigation of GEAS was conducted in grades 6-8) were invited to participate in the study after obtaining their assent and the consent of their parents or guardians.

A total of 1611 adolescents participated in the wave 2 investigation. Of them, $87(5.40 \%)$ were excluded because of missing information on impulsivity (16) or aggressive behaviours (71), respectively. Finally, 1524 eligible students were included in the data analysis.

\section{Procedure}

Data were collected through tablets using the computerassisted self-interview method during November and December in 2018. The students were organised by their teachers in the class units to fill in the electronic questionnaire independently during the lunch break or psychological class. In each class, one to two trained investigators were present in case the participants need assistance with using the tablet. Communication or discussion among participants during the process was dissuaded, while questions regarding the survey could be raised to the available investigators. The questionnaire took approximately 25-40 min to finish. The tablets were returned after the process and checked by the investigators to ensure that all necessary questions were answered before submission. Each student was compensated for their participation with a small gift valued at $¥ 20$ - $¥ 30$ after the process.

\section{Measures}

\section{Aggressive behaviour}

Aggressive behaviour was assessed by two items: (1) During the past 6 months, have you bullied or threatened another boy or girl for any reason?; (2) During the past 6 months, have you slapped, hit, or otherwise physically hurt another boy or girl in any way that they did not want? Each item comprised six options: (1) no; (2) yes, both for girls and boys; (3) yes, for boys; (4) yes, for girls; (5) don't know; (6) refuse to answer. Options 5 and 6 were treated as missing values in data analysis. A student was classified into an aggressor if both or one of the two behaviours listed above exists.

\section{Impulsivity}

Impulsivity was measured by Barratt Impulsivity Scale (BIS-11), a valid and reliable instrument developed by Barratt in 1959 and revised by Patton et al in $1995 .^{32}$ The scale composed of 30 items and is grouped into three subscales: attentional impulsivity (AI, 8 items) describes the tendency to inattention or to make a quick decision; motor impulsivity (MI, 11 items) is about the propensity to act solely on the spur of the moment despite the consequences; non-planning impulsivity (NPI, 11 items) indicates the lack of a plan for daily or long-term actions. ${ }^{32}$ The items were rated by a 4-point Likert-type option from 1 (rarely/never) to 4 (almost always/always). After reversely coding the negatively worded items, we calculated the mean scores of the scales. Higher scores indicated greater impulsiveness. Because of the absence of generalised cut-off values among youth across research, and the interest of us to see the changes of aggressive behaviours with increased levels of impulsivity, we split the continuous mean scores into tertiles in the multivariate regression model (the mean BIS scores of total and subscale for each tertile among boys and girls were exhibited in the online supplemental table 1). The model compared the highest and middle with the lowest tertiles. Previous studies demonstrated the reliability and validity of BIS-11 when used in Chinese children and adolescents, and the polychoric ordinal $\alpha$ values in the present study were 0.62 for AI, 0.81 for NPI and 0.74 for MI, and 0.89 for the total BIS.

\section{Covariates}

Covariates include adolescents' age, binary indicators of gender at the individual level, binary indicators of family structure (only child vs other), perceived care from the primary caregiver that reflects family caring at the family level, number of close friends, experiences of being bullied within 6 months at the school level, as well as perceived support from the neighbourhood.

\section{Data analysis}

The data analysis began with describing and comparing aggressive behaviour, impulsivity, and covariates between boys and girls. Second, the differences of the mean scores of BIS-11 and its subscales between aggressors and nonaggressors were compared using either t-test or Wilcoxon test. Third, due to the lower prevalence of aggressors in the present study, the multivariate Firth logistic regression model $^{33}$ was conducted to assess the association between impulsivity and aggressive behaviour among the total sample, as well as boys' and girls', respectively. Four models were explored for each group using total BIS-11 mean score and the mean score of each subscale (AI, MI and NPI, respectively). In each model, the demographic characteristics, as well as personal and bioecological factors listed above, were controlled. Before modelling, we first examined the cluster effects on the level of school (level 3) and class (level 2) through multilevel zero models to determine if the hierarchical structure statistically exists in our data given the cluster obtained by cluster sampling. We found, however, the effects were statistically insignificant both for boys or girls, and thus the general logistic regression model was chosen for data analysis. The statistical analyses were conducted by Stata SE V.15. The level of significance was set $\alpha=0.05$ at two-tailed. 
Table 1 Description of demographic variables, aggressive behaviours, impulsivity and covariates

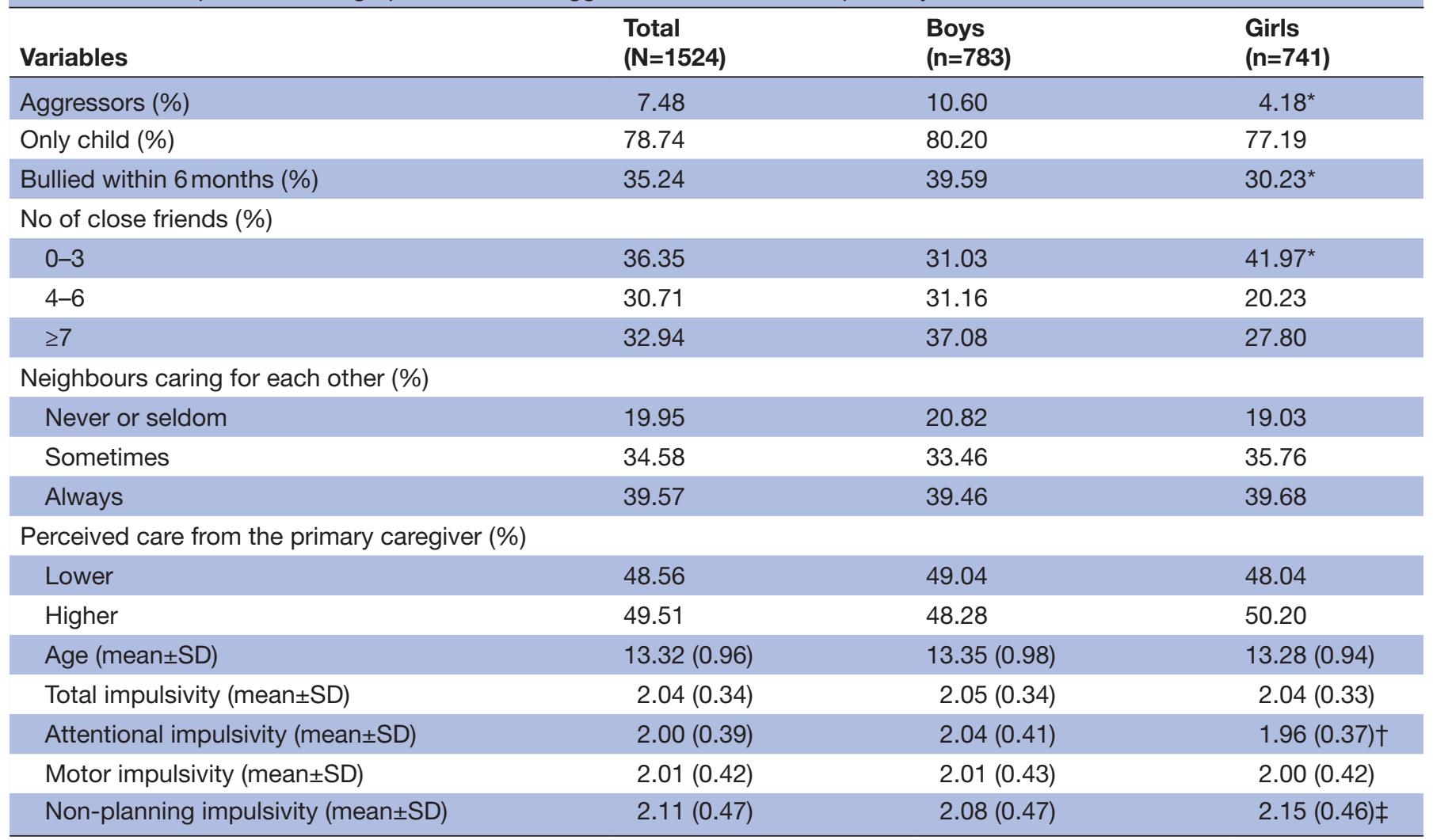

Percentages may not add to $100 \%$ due to missing data.

${ }^{*} \mathrm{P}<0.05, \mathrm{X}^{2}$ test.

$\dagger \mathrm{P}<0.05$, Wilcoxon test.

$\ddagger \mathrm{P}<0.05$, two-sample t-test.

\section{Patient and public involvement}

Young adolescents were invited to test the face validity of the questionnaire in the designing stage. During the survey, all participants were provided with an information sheet about psychosocial resources available to them and an option within the study to indicate interest in supported referrals to services. Adolescents will be invited to join the interpretations of the findings and dissemination stages of the research as well.

\section{RESULTS}

\section{Sample characteristics}

The eligible participants in this study were aged 11-16 years old, with a mean age of $13.32 \pm 0.96$. Boys included in the analysis were slightly more than girls $(51.38 \%$ vs $48.62 \%$ ). Table 1 exhibits the variables used in this study by gender. Compared with boys, girls reported fewer experiences of being bullied within 6 months and fewer close friends. Boys scored higher on AI and lower on NPI. Additionally, gender differences in the proportion of only child, family caring, social cohesion, total impulsivity and MI are statistically insignificant ( $p>0.05$ ), while the prevalence of aggressive behaviours is higher among boys than among girls $(\mathrm{p}<0.05)$.
Score of impulsivity between aggressors and non-aggressors Table 2 shows the comparison of impulsivity between aggressors and non-aggressors by gender. The mean scores of BIS-11 in aggressors were 2.27 and 2.32 among boys and girls, respectively, significantly higher than their counterparts $(p<0.001)$. Moreover, the scores of AI, MI and NPI in aggressors were significantly higher than nonaggressors for both boys and girls $(\mathrm{p}<0.001)$.

\section{Factors associated with aggressive behaviour}

For the total sample, the multivariate logistic regression model results indicated the risk of aggressive behaviours was significantly increased among those with the highest tertile of total impulsivity, AI, MI and NPI compared with those among the lowest tertile (table 3). However, a statistically significant difference was not found among the middle tertile group and the lowest tertile group. Tables 4 and 5 exhibit the results of gender-stratified data analysis for boys and girls, respectively. Similarly, for total impulsivity and MI (model 1 and model 3), the risk of conducting aggressive behaviours significantly increased in the highest tertile group compared with those in the lowest tertile group. However, for AI and NPI (model 2 and model 4), the risk of conducting aggressive 
Table 2 The score $(m e a n \pm S D)$ of impulsivity, grouped by gender and aggressive behaviour

\begin{tabular}{clllllll} 
& Boys & & & & & \\
\cline { 2 - 3 } & Aggressors & Non-aggressors & P value & & Aggressors & Non-aggressors & P value \\
\hline Total impulsivity & $2.27(0.36)$ & $2.02(0.33)$ & $<0.001^{*}$ & $2.32(0.40)$ & $2.03(0.33)$ & $<0.001 \dagger$ \\
Al & $2.27(0.45)$ & $2.02(0.39)$ & $<0.001^{*}$ & $2.20(0.46)$ & $1.95(0.36)$ & $0.002 \dagger$ \\
MI & $2.28(0.51)$ & $1.98(0.41)$ & $<0.001 \dagger$ & $2.33(0.52)$ & $1.99(0.40)$ & $<0.001 \dagger$ \\
NPI & $2.26(0.44)$ & $2.06(0.46)$ & $<0.001^{*}$ & $2.41(0.52)$ & $2.14(0.46)$ & $0.001^{*}$
\end{tabular}

${ }^{*}$ Two-sample t-test.

†Wilcoxon test.

Al, attentional impulsivity; MI, motor impulsivity; NPI, non-planning impulsivity.

behaviours in the highest or middle tertile group was not statistically increased versus the lowest tertile group.

The results suggested that female adolescents were less likely to be an aggressor (table 3). For boys, those who reported a higher level of family caring were less likely to be an aggressor (table 4), whereas such an effect was not significant among girls. On the contrary, older age and higher social cohesion were associated with a lower risk of

Table 3 Factors associated with aggressive behaviours among all samples: results of a multivariate binary Firth logistic regression model

\begin{tabular}{|c|c|c|c|c|}
\hline & Model 1 & Model 2 & Model 3 & Model 4 \\
\hline Variables & OR (95\% Cl) & OR (95\% Cl) & OR (95\% Cl) & OR (95\% Cl) \\
\hline \multicolumn{5}{|l|}{ Age (years) } \\
\hline $14-16$ & $0.54(0.34$ to 0.88$)$ & 0.54 (0.33 to 0.87$)$ & $0.51(0.31$ to 0.83$)$ & 0.54 (0.34 to 0.88$)$ \\
\hline \multicolumn{5}{|l|}{ Gender } \\
\hline Girls & $0.43(0.27$ to 0.70$)$ & $0.48(0.29$ to 0.77$)$ & 0.45 (0.28 to 0.73$)$ & $0.43(0.27$ to 0.70$)$ \\
\hline \multicolumn{5}{|l|}{ No of close friends } \\
\hline $0-3$ & Reference & Reference & Reference & Reference \\
\hline $4-6$ & 1.09 (0.62 to 1.90$)$ & 1.08 (0.62 to 1.90$)$ & $1.10(0.63$ to 1.94$)$ & 1.12 (0.64 to 1.95$)$ \\
\hline \multicolumn{5}{|c|}{ Perceived care from the primary caregiver } \\
\hline Higher & 0.58 (0.35 to 0.94$)$ & 0.57 (0.35 to 0.93$)$ & $0.58(0.35$ to 0.95$)$ & 0.56 (0.35 to 0.92$)$ \\
\hline \multicolumn{5}{|l|}{ Only child } \\
\hline Yes & Reference & Reference & Reference & Reference \\
\hline No & 1.62 (0.99 to 2.68$)$ & 1.62 (0.98 to 2.65$)$ & $1.66(1.01$ to 2.75$)$ & 1.56 (0.95 to 2.57$)$ \\
\hline \multicolumn{5}{|c|}{ Neighbours caring for each other } \\
\hline Never or seldom & Reference & Reference & Reference & Reference \\
\hline Sometimes & $0.65(0.38$ to 1.11$)$ & 0.69 (0.41 to 1.18$)$ & 0.66 (0.39 to 1.12$)$ & 0.66 (0.39 to 1.12$)$ \\
\hline Always & $0.46(0.25$ to 0.83$)$ & 0.45 (0.25 to 0.82$)$ & $0.43(0.23$ to 0.78$)$ & 0.45 (0.25 to 0.82$)$ \\
\hline \multicolumn{5}{|c|}{ Being bullied within 6 months } \\
\hline \multicolumn{5}{|l|}{ Impulsivity } \\
\hline
\end{tabular}

The impulsivity in the models 1, 2, 3 and 4 refers to the total, attentional, motor and non-planning impulsivity, respectively. 
Table 4 Factors associated with aggressive behaviours among boys: results of a multivariate binary Firth logistic regression model

\begin{tabular}{|c|c|c|c|c|}
\hline & Model 1 & Model 2 & Model 3 & Model 4 \\
\hline Variables & OR $(95 \% \mathrm{Cl})$ & OR $(95 \% \mathrm{Cl})$ & OR $(95 \% \mathrm{Cl})$ & OR $(95 \% \mathrm{Cl})$ \\
\hline \multicolumn{5}{|l|}{ Age (years) } \\
\hline $11-13$ & Reference & Reference & Reference & Reference \\
\hline $14-16$ & 0.69 (0.39 to 1.20$)$ & 0.67 (0.38 to 1.16$)$ & 0.65 (0.37 to 1.13$)$ & 0.70 (0.40 to 1.21$)$ \\
\hline \multicolumn{5}{|l|}{ No of close friends } \\
\hline $0-3$ & Reference & Reference & Reference & Reference \\
\hline $4-6$ & 1.25 (0.64 to 2.46$)$ & 1.19 (0.60 to 2.33$)$ & 1.25 (0.63 to 2.46$)$ & 1.26 (0.64 to 2.46$)$ \\
\hline$\geq 7$ & $1.68(0.86$ to 3.27$)$ & 1.48 (0.77 to 2.87$)$ & 1.54 (0.79 to 3.01$)$ & 1.65 (0.84 to 3.21$)$ \\
\hline \multicolumn{5}{|c|}{ Perceived care from the primary caregiver } \\
\hline Lower & Reference & Reference & Reference & Reference \\
\hline Higher & 0.49 (0.27 to 0.88$)$ & 0.47 (0.26 to 0.84$)$ & 0.49 (0.27 to 0.89$)$ & 0.48 (0.27 to 0.87$)$ \\
\hline \multicolumn{5}{|l|}{ Only child } \\
\hline Yes & Reference & Reference & Reference & Reference \\
\hline No & 1.35 (0.72 to 2.53$)$ & 1.40 (0.75 to 2.62$)$ & 1.35 (0.72 to 2.54$)$ & 1.30 (0.69 to 2.43 ) \\
\hline \multicolumn{5}{|c|}{ Neighbours caring for each other } \\
\hline Never or seldom & Reference & Reference & Reference & Reference \\
\hline Sometimes & $0.81(0.42$ to 1.55$)$ & $0.87(0.46$ to 1.67$)$ & $0.85(0.44$ to 1.64$)$ & $0.82(0.43$ to 1.56$)$ \\
\hline Always & 0.59 (0.28 to 1.21$)$ & $0.58(0.28$ to 1.20$)$ & 0.55 (0.27 to 1.13$)$ & 0.55 (0.27 to 1.13$)$ \\
\hline \multicolumn{5}{|c|}{ Being bullied within 6 months } \\
\hline No & Reference & Reference & Reference & Reference \\
\hline Yes & 6.93 (3.56 to 13.50$)$ & 7.20 (3.70 to 13.99$)$ & 7.17 (3.67 to 14.01$)$ & 7.49 (3.86 to 14.53$)$ \\
\hline \multicolumn{5}{|l|}{ Impulsivity } \\
\hline Lowest tertile & Reference & Reference & Reference & Reference \\
\hline Middle tertile & 1.86 (0.82 to 4.22$)$ & 0.84 (0.38 to 1.88$)$ & 1.20 (0.57 to 2.54$)$ & 1.41 (0.68 to 2.91$)$ \\
\hline Highest tertile & 3.14 (1.48 to 6.65$)$ & 1.96 (0.99 to 3.89$)$ & 2.91 (1.46 to 5.82$)$ & 1.82 (0.89 to 3.72 ) \\
\hline
\end{tabular}

The impulsivity in models 1, 2, 3 and 4 refers to the total, attentional, motor and non-planning impulsivity, respectively.

aggressive behaviours among girls (table 5), while these effects were not significant among boys. Being bullied within 6 months may significantly increase the risk of aggressive behaviours for both boys and girls. However, the number of close friends and family structure (only child) showed no significant associations with aggressive behaviours in this study (tables 4 and 5).

\section{DISCUSSION}

The present study sought to add to our knowledge about the relationship between impulsivity and aggression among adolescents by exploring this relationship in a sample of Chinese primary/middle-school students. Positive associations were found between the higher levels of total impulsivity and aggressive behaviours, demonstrating the consistent relationship between impulsivity and aggression. ${ }^{7} 83455$ The physiological mechanism of impulsivity was generally considered as an excitatory response produced by the nervous system; when stimulated by internal or external factors, it may give rise to an intense emotional state within a short period. This emotion constitutes the basis for aggressive behaviour. ${ }^{13}$ On the one hand, an individual with high MI can be more decisive and courageous on the spur of impulses in the face of unexpected opportunities or challenges and difficulties. On the other hand, if an individual lacks the cognitive resources necessary to manage impulses (of high AI), they can be driven by desire or anger to conduct aggressive behaviours, resulting in a range of adverse outcomes. ${ }^{36}$

Studies among forensic and clinical samples found high impulsiveness in both types of aggression, with no significant difference in total scores measured by BIS. ${ }^{122}$ Studies in ordinary western people indicated that the nonplanning subtrait of impulsivity was related to impulsive aggression. ${ }^{37}$ In our sample, however, the correlation of NPI and aggression is not clearly supported. In the multivariate model of our study, a higher level of MI was the only subtrait that significantly contributed to aggressive behaviours among both boys and girls, suggesting 
Table 5 Factors associated with aggressive behaviour among girls: results of a multivariate binary Firth logistic regression model

\begin{tabular}{|c|c|c|c|c|}
\hline & Model 1 & Model 2 & Model 3 & Model 4 \\
\hline Variables & OR $(95 \% \mathrm{Cl})$ & OR $(95 \% \mathrm{Cl})$ & OR $(95 \% \mathrm{Cl})$ & OR $(95 \% \mathrm{Cl})$ \\
\hline \multicolumn{5}{|l|}{ Age (years) } \\
\hline $11-13$ & Reference & Reference & Reference & Reference \\
\hline $14-16$ & 0.33 (0.12 to 0.89$)$ & 0.34 (0.13 to 0.89$)$ & 0.32 (0.12 to 0.86$)$ & 0.34 (0.13 to 0.90$)$ \\
\hline \multicolumn{5}{|l|}{ No of close friends } \\
\hline $0-3$ & Reference & Reference & Reference & Reference \\
\hline $4-6$ & 0.80 (0.29 to 2.18$)$ & 0.87 (0.32 to 2.34$)$ & 0.92 (0.34 to 2.50$)$ & 0.91 (0.33 to 2.48$)$ \\
\hline$\geq 7$ & 1.27 (0.50 to 3.23$)$ & $1.26(0.50$ to 3.17$)$ & $1.26(0.49$ to 3.24$)$ & $1.33(0.52$ to 3.40$)$ \\
\hline \multicolumn{5}{|c|}{ Perceived care from the primary caregiver } \\
\hline Lower & Reference & Reference & Reference & Reference \\
\hline Higher & 0.93 (0.39 to 2.21$)$ & 0.93 (0.38 to 2.26$)$ & 0.90 (0.38 to 2.13$)$ & 0.86 (0.37 to 2.03$)$ \\
\hline \multicolumn{5}{|l|}{ Only child } \\
\hline Yes & Reference & Reference & Reference & Reference \\
\hline No & 2.15 (0.94 to 4.92$)$ & 2.08 (0.91 to 4.77$)$ & $2.20(0.94$ to 5.15$)$ & 2.00 (0.87 to 4.58$)$ \\
\hline \multicolumn{5}{|c|}{ Neighbours caring for each other } \\
\hline Never or seldom & Reference & Reference & Reference & Reference \\
\hline Sometimes & $0.47(0.19$ to 1.17$)$ & $0.47(0.19$ to 1.16$)$ & $0.43(0.17$ to 1.09$)$ & $0.46(0.19$ to 1.16$)$ \\
\hline Always & $0.30(0.10$ to 0.86$)$ & $0.31(0.11$ to 0.88$)$ & $0.28(0.10$ to 0.81$)$ & $0.32(0.11$ to 0.92$)$ \\
\hline \multicolumn{5}{|c|}{ Being bullied within 6 months } \\
\hline No & Reference & Reference & Reference & Reference \\
\hline Yes & 9.65 (3.38 to 27.55$)$ & 10.24 (3.61 to 29.06$)$ & 10.08 (3.53 to 28.76$)$ & 10.09 (3.55 to 28.65$)$ \\
\hline \multicolumn{5}{|l|}{ Impulsivity } \\
\hline Lowest tertile & Reference & Reference & Reference & Reference \\
\hline Middle tertile & 2.67 (0.69 to 10.37$)$ & 1.64 (0.56 to 4.83$)$ & 1.38 (0.44 to 4.32$)$ & $1.15(0.31$ to 4.34$)$ \\
\hline Highest tertile & 3.74 (1.10 to 12.76$)$ & 2.13 (0.73 to 6.19$)$ & 3.57 (1.25 to 10.20$)$ & 2.75 (0.91 to 8.36$)$ \\
\hline
\end{tabular}

The impulsivity in the models 1, 2, 3 and 4 refers to the total, attentional, motor and non-planning impulsivity, respectively.

that the aggressive behaviours among Chinese youth are conducted in adolescence majorly because of the act without thinking. Though the effects of attentional and non-planning impulsiveness were not statistically significant, there was a consistent trend in the multivariate model that the risk of conducting aggressive behaviours rose when the impulsive level increased. Our result indicated that it might be the critical window for early intervention during the adolescence period before the subtrait and related cognitive deficit triggered the harmful behaviour.

Bronfenbrenner's bioecological model supports the finding in our study that better family care was negatively related to adolescent boys' aggression. The result is also in line with the family coercion theory, which assumes that positive family interactions decrease boys' problem behaviours. ${ }^{33}$ Insufficient family care might contribute to adolescents' aggressive behaviours in many ways: less monitoring and lack of adults to confide in when anger is triggered because of events and processes in the environment. Further, those adolescents who have grown up with less family care are more likely to elicit negative responses from their parents as they begin to assert their autonomy and independence. These negative interactions are likely to result in increasingly aversive and coercive processes, putting adolescents at a higher risk of aggression and other behavioural problems. ${ }^{34}$ Interestingly, such a finding was only positive among boys. It might be because female students are less likely to behave in aggressive ways physically and are always required to be quiet, gentle and polite under Chinese culture, which does not distinguish between aggressors and non-aggressors.

A previous study has demonstrated that social and environmental factors were the principal influences of aggression and that neighbourhood support was a significant protective factor against attack. ${ }^{37}$ Our study also indicated that adolescent girls' neighbourhood support might significantly decrease their likelihood of aggressive behaviours. Poor neighbourhood environment-characterised by high levels of violence, anger and disapproval, and low warmth and support-has been reported to be associated with an increased risk of behaviour problems 
and delinquency and aggression in adolescents. ${ }^{38} \mathrm{In}$ contrast, students were likely to feel more supportedand less aggressive-in a neighbourhood that provides adequate resources and assistance for youth healthy growth and development, such as after-school programming and recreational spaces. ${ }^{39}$ These resources may lead to less aggressive behaviour by encouraging social networks and bonding within the neighbourhood. ${ }^{37}$

Adolescent aggressors tend to have higher levels of life stress than their counterparts without such behaviours. ${ }^{40}$ Since the school has become the primary arena for an adolescent, stressors caused by discordant school relationships were expected, such as peer conflicts or bullying. ${ }^{40}$ Consistent with the bioecological model as well as the previous research that school-related tensions were significant predictors of aggression, ${ }^{33}$ our study also suggested that peer bullying was associated with a higher risk of aggressive behaviour. Adolescents with bullying experience are likely to breed a negative intention of hostility and revenge. If the resulting negative emotions are not handled properly, it will cause aggressive behaviour once the victim has an opportunity to retaliate. Furthermore, adolescents tend to have a strong ability to imitate. The bullying or aggression of their schoolmates may set a bad example, and thus they might behave similarly in certain conditions. This finding implies the efforts to reduce youth aggression by providing appropriate support and services to those students who have already been bullied by their schoolmates or peers.

The result of the present study indicated that female adolescents were less likely to be involved in aggressive behaviour toward others than their male counterparts. Females tend to have less physical strength than males; thus, they are less likely to resort to violence to solve problems. Previous studies have demonstrated that girls were prone to social aggression. ${ }^{38}$ Though this study included verbal and social aggression in the outcome related to bullying (see online supplemental tables 2 and 3 for multivariate analysis using bullying and physical attack as outcomes separately), the main focus was still on physical aggression. Thus, the girls' aggressive behaviours may be underestimated.

We compared the prevalence of aggressive behaviour in our study with previous studies implemented in Chinese settings. Given the range of reported published estimates from 3.27\% among middle-school students in Hubei Province to $19.80 \%$ of middle-school students in Henan Province, ${ }^{39}{ }^{40}$ our results suggested a moderate prevalence estimate of aggressive behaviour. This variation may partially be explained by various social conditions (eg, economic status, cultural environment, social security) and sample ascertainment methods in different studies. The lack of standardised definition and measurement methods for adolescent aggression may also contribute to the variation. The prevalence of aggressive behaviour in our sample is significantly lower than that among either Asian Americans or any other racial/ethnic groups (white, black, Hispanic) in the USA, according to the result from the Youth Risk Behavior Surveillance System, suggesting that cultural factors might work as modifiers between impulsivity and aggression. ${ }^{41}$ A study among Chinese and Canadian adolescents suggested that in eastern cultures, individuals tend to define themselves in the context of social relationships and group membership. Thus, the expression of self-focused emotions is discouraged, and peacefulness is highly valued. ${ }^{42}$ However, such a trend might decrease as the age increases or the living environment changes, indicating the necessity to employ a developmental view of behavioural changes when considering the cultural influences.

Naturally, there are limitations to this study. First, the results cannot provide firm conclusions regarding the causal effects proposed because of the cross-sectional design. Second, this study's aggressive behaviours were assessed by two self-reported items, which may result in the underestimation of aggression. Third, instead of using sum-up scores, we used the tertile to categorise the BIS score in the interest of making better use of existing data. Statistically, it would assume an underlying qualitative difference between the groups, although such assumption may not exist or be replicated by other studies. However, we did calculate the summary score of impulsivities, grouped by gender and aggressive behaviour (online supplemental table 4); the result is consistent with what we presented using tertile splits. Besides, we did not distinguish impulsive aggressive behaviours from premeditated aggressive behaviours. Further studies are needed to explore how each facet of impulsivity plays the role in these two forms of aggressive behaviours. To better understand their different biological, psychological social aetiological factors would help with making management strategies. Lastly, our findings may be affected by selection bias due to missing data. However, given the proportion of the enrolled students excluded in the present study was less than $6 \%$, and we use more robust analytical strategies, the bias was adequately controlled.

Aggression is one of the basic human traits aiding in the mechanism of survival. As part of our make-up, it is human nature to be aggressive towards someone occasionally. Teachers, researchers and health promoters need to tell students that there are times and places where aggression is acceptable. They could also teach adolescents to learn how to channel aggression to the areas where it is appropriate and useful. Our study's result does not imply that any individual trait or factor is to be blamed for being the cause of aggressive and violent behaviours. It is always debatable whether impulsivity signals healthy or unhealthy trends in the evolutionary adaptation. Instead, we believe that learning what combination of factors contributes to it could point to leads for designing the intervention strategies to help young adolescents. That said, it is essential to understand that aggressive and violent behaviours continue to be as much a reality in schools and society at large. Helping young adolescents learn to control their impulsiveness, channelling the anger, and helping those at higher risks of being 
aggressive could be approached to improving all adolescents' physical and psychological well-being rather than only taking disciplinary action against aggressors.

\section{CONCLUSIONS}

Despite the limitations, this study contributes to the growing body of research that tries to delve into the relation between three subtraits of impulsivity and aggressive behaviours through a sample of Chinese middle-school adolescent students. Consistent with research in other populations, a positive association between impulsivity and aggressive behaviours was found. Specifically, such correlation was more salient between motor impulsiveness subtrait and aggressive behaviour among boys and girls. Furthermore, results also indicated that aggressive behaviours were affected by several factors within the bioecological model. Comprehensive intervention strategies such as controlling the aggressor's impulsivity, teaching them to channel their anger, creating a supportive and nurturing school and neighbourhood environment as well as providing psychological support and services for victims of violence are needed.

\section{Author affiliations}

${ }^{1}$ Department of Epidemiology and Social Science, NHC Key Lab of Reproduction Regulation (Shanghai Institute for Biomedical and Pharmaceutical Technologies), Fudan University, Shanghai, China

2Department of Epidemiology and Social Science, NHC Key Lab of Reproduction Regulation (Shanghai Institute for Biomedical and Pharmaceutical Technologies), School of Public Health, Fudan University, Shanghai, China

Acknowledgements The GEAS is a multinational study that aims to understand the development of gender norms in early adolescence and its impacts on adolescent health across time and geographies. The study operates in conjunction with the WHO and the Johns Hopkins Bloomberg School of Public Health. Support for the study is made possible in part by the US Agency for International Development (USAID), the WHO, the David and Lucile Packard Foundation, the Bill and Melinda Gates Foundation, the Oak Foundation, and the United Nations Children's Fund. We wish to acknowledge all partners and funders for their support. We would also thank all researchers and students who participate in the study, as well as administrators and teachers in target schools.

Contributors CL initiated the GEAS in Shanghai as a coordinator and project leader. $\mathrm{CL}$ and $\mathrm{XZ}$ contributed to the study design. $\mathrm{CY}, \mathrm{XZ}, \mathrm{QL}, \mathrm{XT}$ and $\mathrm{CL}$ contributed to data collection. $\mathrm{CY}$ and $\mathrm{JZ}$ conducted the data analysis and drafted the paper. All authors are involved in the revising of the manuscript and read and approved the final manuscript.

Funding The present study was funded by the Innovation-oriented Science and Technology Grant from NHC Key Laboratory of Reproduction Regulation (CX201705), and the Innovation-oriented Youth Science and Technology Grant (Q2018-1) from Shanghai Institute for Biomedical and Pharmaceutical Technologies.

\section{Competing interests None declared.}

Patient consent for publication Not required.

Ethics approval The GEAS in Shanghai was approved by the Medical Ethical Committee of the Shanghai Institute for Biomedical and Pharmaceutical Technologies (formerly named Shanghai Institute of Planned Parenthood Research, No. PJ2017-27); a deemed exempt for secondary data analysis was approved by the Johns Hopkins Bloomberg School of Public Health Institutional Review Board.

Provenance and peer review Not commissioned; externally peer reviewed.

Data availability statement Data are available upon reasonable request. Deidentified data are available upon reasonable request, but the approval of institutional review board will be necessary. Please contact the corresponding author for detail or email to: chunyanyu@outlook.com.
Supplemental material This content has been supplied by the author(s). It has not been vetted by BMJ Publishing Group Limited (BMJ) and may not have been peer-reviewed. Any opinions or recommendations discussed are solely those of the author(s) and are not endorsed by BMJ. BMJ disclaims all liability and responsibility arising from any reliance placed on the content. Where the content includes any translated material, BMJ does not warrant the accuracy and reliability of the translations (including but not limited to local regulations, clinical guidelines, terminology, drug names and drug dosages), and is not responsible for any error and/or omissions arising from translation and adaptation or otherwise.

Open access This is an open access article distributed in accordance with the Creative Commons Attribution Non Commercial (CC BY-NC 4.0) license, which permits others to distribute, remix, adapt, build upon this work non-commercially, and license their derivative works on different terms, provided the original work is properly cited, appropriate credit is given, any changes made indicated, and the use is non-commercial. See: http://creativecommons.org/licenses/by-nc/4.0/.

\section{ORCID iDs}

Chunyan Yu http://orcid.org/0000-0002-5550-3823

Qiguo Lian http://orcid.org/0000-0001-8307-0116

\section{REFERENCES}

1 Stanford MS, Houston RJ, Mathias CW, et al. Characterizing aggressive behavior. Assessment 2003;10:183-90.

2 Bushman BJ, Anderson CA. Is it time to pull the plug on the Hostile versus instrumental aggression dichotomy? Psychol Rev 2001;108:273-9.

3 Estévez E, Jiménez TI, Moreno D. Aggressive behavior in adolescence as a predictor of personal, family, and school adjustment problems. Psicothema 2018;30:66-73.

4 Obeid S, Saade S, Haddad C, et al. Internet addiction among Lebanese adolescents: the role of self-esteem, anger, depression, anxiety, social anxiety and fear, impulsivity, and Aggression-A crosssectional study. J Nerv Ment Dis 2019;207:838-46.

5 Schmits E, Glowacz F. Delinquency and drug use among adolescents and emerging adults: the role of aggression, impulsivity, empathy, and cognitive distortions. J Subst Use 2019;24:162-9.

6 Wang L, He CZ, Yu YM, et al. Associations between impulsivity, aggression, and suicide in Chinese college students. BMC Public Health 2014;14:551.

7 Evans SC, Fite PJ, Hendrickson ML, et al. The role of reactive aggression in the link between Hyperactive-Impulsive behaviors and peer rejection in adolescents. Child Psychiatry Hum Dev 2015;46:903-12.

8 MacDonell ET, Willoughby T. Investigating honesty-humility and impulsivity as predictors of aggression in children and youth. Aggress Behav 2020;46:97-106.

9 Ehrenreich SE, Beron KJ, Underwood MK. Social and physical aggression trajectories from childhood through late adolescence: predictors of psychosocial maladjustment at age 18. Dev Psychol 2016;52:457-62.

10 Sigurdson JF, Undheim AM, Wallander JL, et al. The long-term effects of being bullied or a bully in adolescence on externalizing and internalizing mental health problems in adulthood. Child Adolesc Psychiatry Ment Health 2015;9:42.

11 Huesmann LR, Dubow EF, Boxer P. Continuity of aggression from childhood to early adulthood as a predictor of life outcomes: implications for the adolescent-limited and life-course-persistent models. Aggress Behav 2009;35:136-49.

12 Kokko K, Pulkkinen L, Huesmann LR, et al. Intensity of aggression in childhood as a predictor of different forms of adult aggression: a Two-Country (Finland and United States) analysis. J Res Adolesc 2009;19:9-34.

13 Hamilton KR, Mitchell MR, Wing VC, et al. Choice impulsivity: definitions, measurement issues, and clinical implications. Personal Disord 2015;6:182-98.

14 Stanford MS, Mathias CW, Dougherty DM, et al. Fifty years of the Barratt Impulsiveness scale: an update and review. Pers Individ Dif 2009;47:385-95.

15 Mahon K, Burdick KE, Wu J, et al. Relationship between suicidality and impulsivity in bipolar I disorder: a diffusion tensor imaging study. Bipolar Disord 2012;14:80-9.

16 Azevedo J, Vieira-Coelho M, Castelo-Branco M, et al. Impulsive and premeditated aggression in male offenders with antisocial personality disorder. PLoS One 2020;15:e0229876.

17 Urben S, Habersaat S, Pihet S, et al. Specific contributions of age of onset, callous-unemotional traits and impulsivity to reactive and 
proactive aggression in youths with conduct disorders. Psychiatr $Q$ 2018;89:1-10.

18 Martin S, Zabala C, Del-Monte J, et al. Examining the relationships between impulsivity, aggression, and recidivism for prisoners with antisocial personality disorder. Aggress Violent Behav 2019;49:101314.

19 Soloff P, White R, Diwadkar VA, Impulsivity DVA. Impulsivity, aggression and brain structure in high and low lethality suicide attempters with borderline personality disorder. Psychiatry Res 2014;222:131-9.

20 Franco C, Amutio A, López-González L, et al. Effect of a mindfulness training program on the impulsivity and aggression levels of adolescents with behavioral problems in the classroom. Front Psychol 2016;7:1385.

21 Wasserman AM, Mathias CW, Hill-Kapturczak N, et al. The development of impulsivity and sensation seeking: associations with substance use among at-risk adolescents. J Res Adolesc 2020;30:1051-66.

22 Barratt ES, Stanford MS, Dowdy L, et al. Impulsive and premeditated aggression: a factor analysis of self-reported acts. Psychiatry Res 1999;86:163-73.

23 Maneiro L, Cutrín O, Gómez-Fraguela XA. Gender differences in the personality correlates of reactive and proactive aggression in a Spanish sample of young adults. J Interpers Violence 2020:886260520957697.

24 Blum RW, Astone NM, Decker MR, et al. A conceptual framework for early adolescence: a platform for research. Int $J$ Adolesc Med Health 2014;26:321-31.

25 Austerman J. Violence and aggressive behavior. Pediatr Rev 2017;38:69-80.

26 Kramer-Kuhn AM, Farrell AD. The promotive and protective effects of family factors in the context of peer and community risks for aggression. J Youth Adolesc 2016;45:793-811.

27 Browning CR, Burrington LA, Leventhal T, et al. Neighborhood structural inequality, collective efficacy, and sexual risk behavior among urban youth. J Health Soc Behav 2008;49:269-85.

28 Austerman J. Violence and aggressive behavior. Pediatr Rev 2017;38:69-80.

29 Deng L, Wu Y, Kong R. Interactive influence of Impulsiveness and parent-adolescent communication on adolescents' Internet addiction (in Chinese). Psychological Development and Education 2014;30:169-76.

30 Lu X, Zhu F, Liu Y. A comparative study of impulsivity and selfconsciousness between depressive adolescents with and without nonsuicidal self-injury (in Chinese). Journal of Psychiatry 2018;31:325-7.

31 Zhang W, Liu N, Wang C. Relationship between childhood trauma,impulsivity and suicide ideation in patients with borderline per-sonality disorder(in Chinese). Journal of Clinical Psychiatry 2017;27:19-21.

32 Patton JH, Stanford MS, Barratt ES. Factor structure of the Barratt impulsiveness scale. J Clin Psychol 1995;51:768-74.

33 Heinze G, Schemper M. A solution to the problem of separation in logistic regression. Stat Med 2002;21:2409-19.

34 Hahn AM, Simons RM, Simons JS, et al. Prediction of verbal and physical aggression among young adults: a path analysis of alexithymia, impulsivity, and aggression. Psychiatry Res 2019;273:653-6.

35 Sarkisian K, Van Hulle C, Lemery-Chalfant K, et al. Childhood inhibitory control and adolescent impulsivity and novelty seeking as differential predictors of relational and overt aggression. J Res Pers 2017;67:144-50.

36 Pérez Fuentes MDC, Molero Jurado MDM, Carrión Martínez $\mathrm{JJ}$, et al. Sensation-Seeking and impulsivity as predictors of reactive and proactive aggression in adolescents. Front Psychol 2016;7:1447.

37 Ramírez JM, Andreu JM. Aggression, and some related psychological constructs (anger, hostility, and impulsivity); some comments from a research project. Neurosci Biobehav Rev 2006;30:276-91.

38 Liu Y, Kuang L, Ai M. Investigation of gender differences of suicidal, impulsive and aggressive behavior among Chongqing college students (in Chinese). Chin J Sch Health 2015;36:333-6.

39 Wang J, Yu Y. Case control study on personality character and risk factors of the students with aggressive behavior (in Chinese). Chin J Sch Health 2006;3:222-3.

40 Sun L, Heng S, Niu G. Association between childhood psychological abuse and aggressive behavior in adolescents: the mediating role of the security and loneliness (In Chinese). Chin J Clinical Psychol 2017;25:902-6.

41 Lowry R, Eaton DK, Brener ND, et al. Prevalence of health-risk behaviors among Asian American and Pacific Islander high school students in the U.S., 2001-2007. Public Health Rep 2011;126:39-49.

42 Jia F, Li L, Krettenauer T. Self- and other-evaluative moral emotions in prosocial contexts: a comparison of Chinese and Canadian adolescents. Psych J 2019;8:203-11. 